\title{
Ministries of Health and the Stewardship of Health Evidence
}

\author{
Justin Parkhurst, Arturo Alvarez-Rosete, Stefanie Ettelt, \\ Benjamin Hawkins, Marco Liverani, Elisa Vecchione, \\ and Helen Walls
}

\section{INTRODUCTION}

This chapter brings together insights of parallel efforts to map out the structures and bodies providing evidence to inform health policy in the six GRIP-Health case study countries covered in this volume of work. More specifically, it reflects on the roles of Ministries of Health in each country, and the systems of evidence advice that provide policy relevant evidence to

J. Parkhurst $(\bowtie)$

London School of Economics and Political Science, London, UK e-mail: j.parkhurst@Ise.ac.uk
A. Alvarez-Rosete
- S. Ettelt •
B. Hawkins
M. Liverani • E. Vecchione

- H. Walls

London School of Hygiene and Tropical Medicine, London, UK

e-mail: arturo.alvarez-rosete@1shtm.ac.uk; stefanie.ettelt@lshtm.ac.uk;

ben.hawkins@lshtm.ac.uk; marco.liverani@lshtm.ac.uk; e.vecchione@ucl.ac.uk;

helen.walls@lshtm.ac.uk

(C) The Author(s) 2018

J. Parkhurst et al. (eds.), Evidence Use in Health Policy Making, International Series on Public Policy, https://doi.org/10.1007/978-3-319-93467-9_8 
these Ministries. This chapter describes how Ministries of Health have been mandated to act as stewards of populations' health according to the World Health Organization. We argue that this mandate extends to them having (at least partial) responsibility for ensuring relevant evidence and information informs health policy decisions. The chapter then discusses the need to consider evidence advisory systems serving Ministry needs, particularly considering whether or how such systems work to provide relevant and salient information in a timely manner to key decision points in the policy making process. Insights from our six cases are presented to illustrate the structural and practical differences which exist between evidence advisory systems and how, at certain times, key health decisions may in fact lie outside ministerial authority. These divergent experiences highlight a range of analytical challenges when considering the provision of evidence to inform health decisions from an institutional perspective. The following chapter continues the discussion with country case studies and comparative reflections on the use of evidence within government bodies outside Ministries of Health - particularly in the legislature and judiciary.

\section{Ministries as Stewards of Health and Health Evidence}

A key debate in global health over the last two decades has concerned the role of the state in the health sector and in health systems governance (WHO 2000, p. 119; Saltman and Ferroussier-Davis 2000, p. 732; Reich 2002; Alvarez-Rosete 2008). This has grown in part from a renewed focus on the importance of health systems for improving population health, while simultaneously acknowledging the increasing diversity of decisionmaking forums and agencies involved in healthcare provision and implementation (Durán et al. 2011; Hafner and Shiffman 2012). (Dodgson et al. 2002) These changes have led to a shift in the vocabulary used by scholars. The term 'governance' began to replace 'government' within political science discourse since the 1990s, reflecting the decentred position of central government in public policy in many countries (Rhodes 1996, 1997; Kooiman 2000; Pierre 2000; Rosenau 1995; Stoker 1998). ${ }^{1}$ These changes have occurred in parallel with the growing number of calls to ensure that health services, and wider health sector, planning is informed

\footnotetext{
${ }^{1}$ For overviews of this shift in terminology and focus, see: (Bell and Hindmoor 2009; Richards and Smith 2002; Piere and Peters 2000; Davies and Keating 2000; Kjaer 2011, 2004).
} 
by the rigorous use of evidence, with a growing body of literature that has engaged with strategies to improve the uptake or use of evidence (c.f. van Kammen et al. 2006; LaRocca et al. 2012; Lavis et al. 2010). Yet in the changing health sector landscape, questions arise about whose role or responsibility it is to ensure health policy is informed by evidence.

Recent decades have also seen widespread debate about the capacity of the state to deliver policy outcomes and its right to intervene in the lives of the citizens it governs (Richards and Smith 2002; Bell and Hindmoor 2009). This shifting conceptualization of government as governance has also occurred in the arena of health (Dodgson et al. 2002; Kickbusch 2002; Lewis et al. 2006). Thus questions have been raised about the locus of political power in contemporary societies and whether the state enjoys the same degree of control and power over health systems and policy as in the past. (Bell and Hindmoor 2009; Bevir 2010; Rhodes 1997) In contemporary health systems, the number of old and new actors and institutions has multiplied, the boundaries between the public and private sectors have become more blurred, and central authorities' control over a much more complex policy process may now be challenged (Lewis et al. 2006; AlvarezRosete 2007; Saltman et al. 2011). The inherent complexity this implies means that such systems can only be governed through processes of steering, coordination and goal-setting for the range of different stakeholders involved and by developing a wide range of tools and strategies to this end.

The World Health Organization (WHO) introduced and championed the concept of stewardship of health systems as an essential government function in the year 2000 World Health Report (hereafter WHR 2000), which was devoted to the understanding, functioning and performance health systems. The report took a broad view of health systems as including: "all the organizations, institutions and resources that are devoted to producing health actions. [Continuing:] A health action is defined as any effort, whether in personal health care, public health services or through intersectoral initiatives, whose primary purpose is to improve health (p. xi)".

The WHR 2000 is widely held up by the health community as a key document championing and reinvigorating the focus on health systems, with ministries of health being seen as health system stewards. Many subsequent WHO reports and policies have aimed at strengthening systems as well as the institutional mechanisms for governing them (WHO 2003, 2007, 2008). Similarly, WHO regional offices have had the intertwined topics of health systems development and state governance roles at the heart 
of their discussions (WHOROE 2008; Kickbusch and Gleicher 2012) - also see (McQueen et al. 2012).

The terms governance and stewardship have often been used as synonyms by those working in the health field, yet stewardship implies a particular mandate, and ultimate responsibility, for population health that is reflected when the WHO states:

The ultimate responsibility for the overall performance of a country's health system lies with government, which in turn should involve all sectors of society in its stewardship $[\ldots]$ The health of the people is always a national priority: government responsibility for it is continuous and permanent. Ministries of health must therefore take on a large part of the stewardship of health systems. (WHO 2000, p. xiv)

According to the WHR 2000, such responsibility is exercised over three distinct dimensions of stewardship (p. 122):

- Formulating health policy - defining the vision and direction;

- Exerting influence - approaches to regulation;

- Collecting and using intelligence.

Whilst the first two components indicate a responsibility to oversee health policy and the conduct of health actors, the third dimension - 'collecting and using intelligence' - captures many of the common ideas about the use of policy relevant information to inform health decisions.

\section{Institutional Systems of Evidence Advise for Health Policy}

Ministries of Health may thus be seen as having a mandate over decisions affecting the health of the people, as well as over the use of evidence and information to guide those decisions. However, effective utilisation of evidence requires a conduit through which it can reach relevant decisionmakers at times when such information can be useful. Thus applying wider 'governance' concepts to the question of evidence use, it becomes clear that Ministries will not necessarily take it upon themselves to gather and analyse all policy relevant evidence (although some of them may try to). Rather, they can serve as the stewards of health evidence by overseeing and maintaining the institutional arrangements in place which serve to provide policy-relevant evidence. 
Ministries can rely on a more or less formalised network of bodies and groups to serve as the providers of policy-relevant evidence (Nutley et al. 2007; Parkhurst 2017) - networks we refer to as 'evidence advisory systems', which can be seen to reflect a specific form of the broader concept of 'policy advisory systems' within the public policy literature. According to Hustedt and Veit (2017), "The concept of policy advisory systems focuses on the country-specific organization and institutionalization of policy advice. It refers to an interlocking set of actors with a unique configuration in each sector and jurisdiction, who provide information, knowledge, and recommendations for actions to policy-makers" (p. 42).

One of the first authors to explicitly discuss policy advisory bodies from an institutional perspective was John Halligan (1995) who explored the location of the body providing advice (within the public service, internal to the government, or external) and reflected on the level of government control each might entail. Halligan notes that there is no consensus as to the 'best' structure for policy advice, but highlights some of the different potential issues that might be raised by differing systems, including the level of independence of the advisory bodies or the level of public consultation involved. He proposes three principles that might be seen as central to a good advisory system, however: the provision of multiple sources of advice; the flexibility to be able to choose a mix of advisors and processes appropriate to a particular issue; and an explicit concern with the effectiveness of advice.

More recently, scholars have questioned whether Halligan's focus on location of advice is necessarily the best factor to consider when judging policy advisory systems. Craft and Howlett (2012), for instance, argue that this focus may ignore a number of other key concerns to those studying advisory systems, including the content of the policy advice itself, which can have important implications for the kinds of decisions advice that is being provided. Other scholars have started to investigate policy advisory systems in greater depth, but according to Hustedt and Veit (2017), much of this work has focussed on western democracies, looking at questions such as the externalisation of advice or politicisation of advice, with a large number of other policy-relevant questions remaining unaddressed. In the health sector, Koon and colleagues (Koon et al. 2013) have more specifically discussed the importance of 'embeddedness' of health policy and systems research to inform health policy decisions; with embeddedness reflecting the centrality and networked links these forms of research have in various government systems. 
However, the explicit normative goal of Ministries of Health to serve in a stewardship role to improve population health provides a useful lens by which to analyse evidence advisory systems. Indeed, while high level legislatures and political bodies may see their ultimate goals continually being debated or changed as political priorities shift, Ministries of Health typically have a fairly commonly agreed set of goals that can be used to reflect on how evidence advisory systems in place work to serve those needs or achieve health sector goals.

Indeed, stakeholders calling for increased or improved uses of evidence in health policy typically make such calls on the basis of a set of (stated or unstated) assumptions. First, the goals of health policy to improve population health - primarily though reducing morbidity and mortality, extending life expectancy, or decreasing health inequalities - are taken as given by many public health advocates. Furthermore, the particular emphasis on scientific evidence is based on an underlying assumption that more rigorous and systematic uses of evidence are likely to lead to greater effectiveness and efficiency than piecemeal or scientifically flawed uses of evidence (Chalmers 2003; Chalmers et al. 2002; Parkhurst 2017). Yet efficiency gains of this nature further require that policy-relevant evidence is produced and reaches the appropriate decision making body in a timely manner in order to be usable. These criteria provide us with a lens through which to evaluate the structures, functions and effectiveness of evidence advisory bodies serving Ministries of Health.

\section{Health Decisions and Needs}

The public policy literature recognises that the term 'policy' can refer to a range of concepts, from projects and programmes, to sector-specific plans, to broad statements of intent (Hogwood and Gunn 1984). Policy is also rarely the responsibility of a single body; rather, policy decisions affecting health take place at difference levels of governance (i.e. sub-national, national and supra-national) across a range of state and non-state decision making forums. As such, the most relevant forms of evidence will vary across policy issues and decision types of policy-making location.

However, there are some types of decisions common to many countries' health sectors for which research evidence is often held as critical, and over which Ministries of Health typically are seen to have authority. This allows a basic typology of decision types to provide a starting point to explore how evidence advisory systems work to provide policy-relevant evidence. For example: 
- Public health and health promotion: Decisions of this kind are usually done at a high level as they affect large segments of the population. A broad range of evidence will thus be relevant to such decisions, including epidemiological, economic, social attitude, and other data which speak to relevant policy concerns.

- Health sector planning and priority setting: These decisions are concerned with setting national goals and priority setting across the sector. They can also involve allocation of resources between local health concerns. Relevant evidence forms can thus include population health data, resource health technology appraisals/assessments (HTA), or health services research.

- Health systems and services management: In addition to new policy decisions and priority setting, Ministries of Health also typically make ongoing decisions related to the management and functioning of the health system. Relevant evidence can include routine data collected from facilities or surveys, operations research, implementation research, or other programmatic evidence.

- Programmatic decision making: What many authors refer to as health policy decisions fall within the remit of specialised agencies, such as programmes dedicated to individual conditions (cancer, HIV/AIDS, malaria, etc.). In particular these decisions can involve the choice of interventions to pursue, often with a fixed budget to allocate. Decisions of this nature can require evidence both about efficacy or cost effectiveness of available options, but equally can be informed by locally generated data (e.g. routine data from surveillance or facility information).

Even within these broad categories, decision making for health can take place at different levels within government hierarchies, with authority for decisions, and entry points for evidence, resting in national level bodies and sub-national bodies. In different country settings the various decision types listed above might be addressed at any level or may cut across more than one. Moreover, they may be shaped by supra-national policy regimes (such as those of the European Union). Movements towards de-centralisation might also lead to the shifting of decisionmaking from national levels to lower levels. Such realities, however, allow consideration of whether systems of evidentiary advice are well aligned with the decision authority structures in a given setting. There can also be important considerations on the ways that national evidence systems 
link to influential non-state decision makers (e.g. development partners in low and middle income settings, or corporatist bodies with authority in health decision making fora).

\section{Country Case Studies}

In each case study country, members of the GRIP-Health research programme attempted to map out the key health policy decision making bodies, and the sources of evidence in the country that inform health decisions. These mappings allowed reflection on how the evidence advisory system in each country might work, or face challenges, in aligning sources of policy relevant evidence with the policy needs in each setting. The subsections below summarise some of the key findings from each case. This is then followed by a discussion of cross cutting issues and themes seen from multiple settings.

\section{Ghana}

In Ghana, the Ministry of Health $(\mathrm{MoH})$ provides overall policy direction for all stakeholders and players in the health sector, and approves health decisions related to specific health system issues, including health system strengthening and, at times, programme or disease specific interventions. The Ghana Health Service (GHS) is an autonomous Executive Agency of the $\mathrm{MoH}$ which has been delegated the responsibility to manage and operate all public health facilities (except for three teaching hospitals); while the National Health Insurance Authority (NHIA) is also the primary body which decides on the package of services available to many citizens.

Ghana has established some formal internal bodies to provide evidence to these agencies. Within the GHS, the Policy, Planning, Monitoring and Evaluation division and the Research \& Development division are both tasked with evidence generation. The GHS also hosts the Centre for Health Information Management which includes the District Health Information Management System, through which routine health data (administrative, demographic and clinical) is provided from local facilities to districts and upwards to central health management levels. In the $\mathrm{MoH}$ there is also a Research, Statistics and Information Management Directorate and a MoH-based Policy, Planning, Monitoring and Evaluation division as well which are responsible for generating evidence and advising the $\mathrm{MoH}$. The GHS also directs three regional research centres that 
conduct health services and systems research within their designated areas to guide national decision making.

In these ways, Ghana appears to have a well-aligned bureaucracy providing relevant research and evidence to key decision making bodies. However we did identify some challenges and further needs as well. First, as a lower-middle income country, there were some expected capacity limitations in terms of volume of research and population of experts to provide relevant evidence. Furthermore, while the NHIA is tasked with choosing the services covered by the National Health Insurance Scheme, the GHS decides the NHIS charges at each facility. Interviews and participatory observations at the annual business meeting with international partners in November 2015, identified a latent rivalry between the two government agencies due to conflicting interests in generating and using evidence to inform decisions as purchaser (NHIA) and provider (GHS) of health services.

At the time of research, there was not any formalised or fully agreed system of Health Technology Appraisal (HTA) in place to guide decisions on health services provided across the health sector, although there was some movement towards using HTA to inform individual decisions. Funding for many health programmes is also reliant on international donors (so called 'development partners'), which was said to lead to vertical programming independent of any evidence of local priorities or need. International donors were also said to use their own systems and bodies of evidence at times.

Reliance on development partners, who can retain decision making authority in some ways, can thus pose challenges to rationalising evidence use and ensuring local stewardship of evidence advisory systems. On the one hand, donors obviously provide finance for health services, and will no doubt at times be undertaking evaluations of programmes that can generate policy relevant evidence. Yet, such systems are external to national structures, and thus risk establishing parallel systems of evidence advisory outside those under the control of, and at the service of, national authorities.

Finally, it was identified that the Ghanaian Parliament had a remit to make decisions around health financing nationally and other health related legislation through the Parliament select committee on health. However, local interviewees noted limited influence of this committee due to financial constraints prohibiting its ability to gather information or undertake inquiries as needed. Also, the involvement of local MPs into the two annual business meetings with development partners is limited, 
with consequent inability to obtain relevant information on future health interventions and leverage their positions at the moment of approving the government budget.

\section{Colombia}

Colombia is the second middle income case study country, included yet its differences with Ghana illustrate just how context-specific health policymaking can be. Since the inception of the Colombian health system in 1993, highly politicised disagreements have been sustained on issues such as the financing of the system (insurance versus taxation based); the involvement of the private sector; and whether limits can or should be placed on the right to health care. Policy debates almost exclusively focus on macro/systemic health sector reforms, to the exclusion of many other health policy issues.

As an insurance based health system, the Ministry of Health and Social Protection (Ministerio de Salud y Protección Social, MSPS) primarily steers health care by setting the mandatory basic service package (the Plan Obligatorio de Salud [POS]) and regulating the system; although it does not have a direct managerial input on health care facilities. However, roles and authority over these functions have also changed or been assigned (or reassigned) between the Ministry and other bodies in recent years. For instance from 2007 a Regulatory Commission for Health was set up to update the package of health services provided in Colombia, but in 2012 it was abolished and the Ministry re-assumed this role (Castro 2014).

The health policy decision making process in Colombia also involves a range of different institutions across the branches of government as well as non-state actors (e.g. civil society organisations, health insurers, service providers, academia and professional organisations). The governance of the health system is thus extremely fragmented, reflecting the complexity of the health system itself (Bernal et al. 2012; Yamin and Parra-Vera 2010). Furthermore, the judiciary plays a particularly important role in health policymaking in Colombia (as discussed in more depth in Chap. 5) as it often serves as the means by which the public challenges insurers on what should be included in the package of services.

The Ministry does have a series of organizations ascribed to it with responsibilities for evidence provision through their mandate to advise on decisions in health, including: the Instituto Nacional de Salud (INS) (the National Health Institute); the Instituto de Evaluación de Tecnologíca en 
Salud (IETS) (Institute of Health Technology Assessment); and the Instituto Nacional de Vigilancia de Medicinas y Alimentos (INVIMA) (National Institute for the Vigilance of Medicines and Food). Yet there is no unique central hub of evidence generation in the Ministry; instead, each unit and directorate within the Ministry appears to be responsible for its own areas of expertise; and these national advisory bodies may thus have limited influence given the fragmented governance of decision making, providing advice to some decision points but not necessarily others.

Overall, some of the biggest challenges to the use of evidence for health policy thus includes the fragmentation of decision making, the politicisation over fundamental elements of health care provision (diverting time and attention away from more specific health service and systems planning) and the lack of central authority vested in the Ministry of Health and Social Protection. In combination, these factors limit how much evidence advisory bodies can influence health policy decisions in 'rational-technical' ways often expected by public health advocates.

\section{Cambodia}

Cambodia was selected as one of our low income setting cases at the time of research, although today it is classified as 'lower-middle income' in World Bank rankings. Despite recent economic growth, it still has limited state provision of health services. Estimates vary, but survey data suggest two-thirds of health spending is financed by consumer out-of-pocket payments ([Cambodia] National Institute of Statistics Directorate for Health 2015), with national demographic and health surveys suggesting only one-fifth of treatments carried out by the public sector.

The $\mathrm{MoH}$ has the mandate to monitor the country's health status, advise central government on health policies and legislation, formulate strategies and develop programmes to address the country's health problems, and implement, monitor and evaluate all health programmes and activities in the country in collaboration with other sectors and agencies. There are also numerous national programmes, centres and institutions important to the Cambodian health system, many of which are issue specific in their remit. These include the National Maternal and Child Health Centre (NMCH), the National Centre for HIV/AIDS, Dermatology and STD (NCHADS) and the National Institute of Public Health (NIPH). These technical health departments and national centres sit within the $\mathrm{MoH}$ structure, and can initiate specific health policies or guidelines 
(Jones and Camboida Economic Associate Centre for Policy Studies 2013). The Ministry of Economics and Finance (MEF) was noted to be one of the most important other decision making bodies in Cambodia affecting health, however, as it is responsible for financing the health system, and particularly important for health policy decisions with budgetary implications in the country. International development partners (donors) are also highly influential in the Cambodian health sector as over half of the public budget is funded by aid (approximately $52 \%$ of the health budget, as estimated in 2011 (World Bank 2011)). Local respondents further noted that research topics are heavily driven by external funders, rather than assessments of health policy priorities by local bodies.

Whilst there appears to be a demand for evidence and research in health policy-making in Cambodia, including language used within Ministry documents of a need for 'evidence based' approaches, this demand does not appear to be deeply embedded in $\mathrm{MoH}$ systems and structures. A considerable amount of research is produced in the sector in the form of reviews and assessments for specific projects or programmes. This work is often conducted by commissioned consultancies, and has been described elsewhere by Jones (2013) to be of variable quality. Jones further notes concern over the supply of policy-relevant data in the country (Jones and Camboida Economic Associate Centre for Policy Studies 2013). Some information sources (or documents collecting data) are institutionalised, however. For example, the annual operational plan (AOP) process and the health management information system (HMIS); although private consultations and treatments (accounting for about $70 \%$ of care) are not captured in the HMIS. Indeed, the Ministry itself has highlighted the need to improve the reliability and policy relevance of the system (Cambodia Ministry of Health 2008). Furthermore it was reported that the Ministry had no way to monitor or gather data from most private providers of health services, despite this capturing a majority of treatment in the country. The domestic research community is also relatively weak in regard to health, particularly due to limited funding and the low strategic importance accorded to research by political actors (Jones and Camboida Economic Associate Centre for Policy Studies 2013).

In terms of technical bodies, the National Institute for Public Health (NIPH) is one of the most notable within the Cambodian system. It is a semi-autonomous institute under the $\mathrm{MoH}$ tasked to undertake research, knowledge translation, and training - although it has reportedly largely focused on training, as no budget has been provided for research activities. 
Given these resource constraints, including limited staffing capacity, the NIPH is not currently considered a strong player in the domestic research community. However, it does appear to have a clear mandate and institutional position to serve an evidence advisory role.

In terms of donor-funded evidence use, research projects are often focussed on programme evaluation. They have often been critiqued for lacking coordination, resulting in duplications of efforts and inefficient use of resources, and lacking integration in terms of data collection and analysis (Jones and Camboida Economic Associate Centre for Policy Studies 2013). There are some efforts to coordinate data and evidence to inform national level strategic planning, however. In particular, the drafting of the Health Strategic Plan, the mid-term review process of the Plan, as well as annual performance reviews are supported by consultation mechanisms in which data are presented and discussed. Most notable is the Technical Working Group for Health, chaired by the Minster of Health, which brings together government and development partners to present and discuss evidence to inform this high level of sector planning and review.

The evidence advisory system for health policy-making in Cambodia thus appears to suffer from limited capacity and a vertical programme orientation - often driven by sources of funds from outside actors (e.g. donors). There is a lack of strategy in the handling of the evidence and knowledge base for the health sector, and management and decisionmaking based on research evidence and analysis is limited in both health policy-making and service delivery. However, policy makers are aware of the need to develop a research agenda for the sector (expressed in interviews and seen in $\mathrm{MoH}$ documents identifying needed improvements), and some $\mathrm{MoH}$ working groups have increasingly been giving attention to this issue. There are also existing institutional bodies that could serve more central or relevant roles in evidence generation or synthesis in the future, with greater capacity and integration into planning processes.

\section{Ethiopia}

Ethiopia served as our second low income case. The country is officially a federation, and the constitution establishes dual jurisdiction over public health between the Federal and the Regional governments. However, the Federal Ministry of Health has control over the national health policy, formulating the national strategic plan for the health sector. Since 1991, Ethiopia has made improvements to health care delivery and set the basic 
foundations of a health system, improvements that are recognized by some as a success story of health system reform (Downie 2016). In this process, the role of health research has been seen to be critical; consequently, Ethiopia has at times made explicit commitments to improving the use of evidence in health (c.f. Ethiopian Academy of Science 2013).

Given the limited resources in country, there have been expected ongoing challenges in terms of low research-related technical and human capacity and an absence of strong research priority-setting mechanisms. Yet these limitations seem not to have undermined the capacity of the Federal Ministry of Health (FMoH) to make decisions in health and enforce commitments with development partners (Downie 2016). Instead, the government of Ethiopia appears to have maintained a strong central controlling function over the decisions which have been made. Health policymaking in Ethiopia appears heavily focussed on centralised planning, and particularly draws on routine data sources to inform decisions. Data gathering and analysis are concentrated in two main national agencies, the Central Statistical Agency and the recently reorganised Ethiopian Public Health Institute. Data on health facilities are collected at the community level, then reported to the district (woreda), regional and national levels. The FMoH then uses data to produce indicators that are passed back to lower levels to elaborate local health plans (Ethiopia Federal Ministry of Health 2014).

The bureaucratic structures in Ethiopia thus appear to be well aligned for this collection and review of local data for planning. The Policy and Planning Directorate within the FMoH hosts the Health Management Information System (HMIS), for instance, which is a key component of the system. According to national documents, the HMIS is also used to identify funding gaps and priorities in order to inform the need for donor assistance (Ethiopia Federal Ministry of Health 2014).

Generation and review of other forms of evidence to inform planning decisions, however, do show limitations. For example, the Ethiopia Public Health Institute serves as a semi-autonomous institution under the FMOH and is the technical arm of the FMOH. Its main tasks are to undertake research on priority health and nutrition problems and on public health emergencies management. Yet the capacity of this body was said to be limited, leading to fairly piecemeal production of policy relevant evidence. For example, a representative from the Technology Transfer and Research Translation Directorate of EHPI noted that there were very few staff to undertake activities, and only a few policy briefs had been produced to inform decision making at that time. 
It is therefore generally indicated that evidence production and use in Ethiopia are still limited, mainly due to insufficient human capacity in generating evidence and in the relatively young establishment of the culture of evidence-informed policy-making (African Health Observatory 2014). Consolidating and publishing existing evidence for policy-making and decision-making has thus been described as limited and unsystematic (Gaym 2008). Yet this stands in contrast to the seemingly well established and centrally controlled system of planning around routine data sources in the country.

\section{England}

England represents the first of our high income case study settings. The country is well known for its tax funded and state provided National Health Service (NHS). Elements of evidence use within the English system are also often held up as exemplars of evidence informed policy. In particular, the National Institute for Health and Care Excellence (NICE) a non-departmental public body that provides clinical guidelines and health technology appraisals for the NHS - has been held up as a role model both domestically and internationally. Within England, it has served as the inspiration for a set of 'what works' centres that aim to emulate the health approach to synthesising evidence of interventions to inform policymaking (UK Government 2013). Globally it has been a template for health technology assessment bodies in other countries (Including Colombia as noted above, and described by Castro (2014) elsewhere).

The Department (Ministry) of Health has overall responsibility for the NHS, public health and social care, within a legislative framework set by Parliament. The Department is supported by 26 agencies and public bodies. Of these, 15 are referred to as 'arm's-length bodies', with different degrees of independence from government. The remaining bodies are advisory non-departmental public bodies, whose role is to assist the Department in "evaluating, investigating and supporting policy" and providing independent scientific expertise (Boyle 2011). The Department is also supported by two executive agencies: the Medicines and Healthcare products Regulatory Agency (MHRA), responsible for regulating medicines, medical devices and blood components for transfusion, and Public Health England (PHE), developing public health and health promotion policy. Finally, NICE is a non-departmental body that provides national guidance and advice for health, public health and social care practitioners, 
as well as quality standards for the provision and the commissioning of these services. This includes the appraisal of new medical technologies using principles of cost-effectiveness (NICE 2017). NICE therefore plays a key role in defining the package of services available to patients in the NHS.

In general, scientific evidence plays a pivotal role in the governance of the NHS. There is a substantial volume of health systems, health services and health policy research produced in the UK (in addition to clinical research and basic sciences) which has led some authors to describe a culture of evidence use in which the NHS aims to become, a "consistent, evidence-based whole (Shergold and Grant 2008, p. 7)" with substantial 'absorptive capacity' for publicly and privately-funded health research (Hanney et al. 2010).

The evidence advisory system, however, combines multiple elements. In Parliament, select committees play a key role in holding the government to account for its decisions, policies, and reforms; and they mostly do so in relation to health policy through an assessment of the available evidence base. The Department of Health, however, has a history of commissioning research on behalf of the NHS, PHE and others, and of collaborating with the various government research bodies that fund health related research. The National Institute of Health Research (NIHR) was created in 2006, and coordinates research efforts to inform the health system. Finally, England is a leading market for think tanks, including in the health sector. However it has been argued that little is known about how such think tanks prioritize topics, fund their research (and the methodologies employed), or influence health policy-making; with calls for greater research into their roles and biases in health policy-making (Shaw et al. 2014). Despite this, overall the English system has widely been seen as a strong example of a coordinated evidence advisory system that attempts to institutionalise evidence use in health policy and health system governance.

\section{Germany}

Germany represents our final case study country and second high income setting, but one that looks very different from England in its health system structure and broader governance approach. One of the most relevant features, perhaps, is how much health decision making takes place outside the remit of the Ministry of Health. Germany is a federal parliamentary 
republic comprised of 16 states (Lünder). The Basic Law (Grundgesetz) provides for the separation of powers between the Bund (federal state) and the Länder and sets out their respective rights and responsibilities. The Basic Law also sets out the general principles that shape health system governance, including a commitment to 'corporatism' - which broadly involves governance through power sharing with major interest groups. Responsibilities for health system governance are thus shared by federal, states and municipalities, as well as the corporatist self-administration.

Parliamentary decision-making is prepared by, and largely happens in, committees. For health policy, two standing committees are most relevant: the Health Committee (Gesundheitsausschuss) and the Conciliation Committee (Vermittlungsausschuss). Health care legislation, including major health care reform, is usually initiated by the federal minister of health. The main responsibility of the Federal Ministry of Health is to maintain, secure and advance an effective statutory health system ([Germany] Federal Ministry of Health 2015). The Federal Ministry of Health has several ways of steering health and health care policy: developing legislation, decrees and administrative directives; supervising the provision of tasks that have been delegated to the self-administration; and co-ordinating stakeholders in health system governance in other ways, for example, through organising initiatives, establishing committees or promoting other forms of collaborative work.

However, in line with the Basic Law, a large number of decision-making and regulatory tasks have been delegated to the organisations of the selfadministration. At federal level, key corporatist actors are the top organisations of sickness funds (Spitzenverband der deutschen Krankenkassen), representing public payers, the German Hospital Association (Deutsche Krankenhausgesellschaft) and the federal association of office-based doctors and dentists who deliver services funded by social health insurance (Kassenärztliche Bundesvereinigung). Within this self-administration, the Federal Joint Committee (GBA) is the highest decision-making body at federal level, composed of these federal associations.

The Federal Ministry of Health is advised by a number of permanent or temporary expert committees. Permanent committees are the Advisory Council on the Assessment of Developments in the Health Care System and the Joint Scientific Council of the Agencies and Institutes, subordinate to the Ministry. Both committees largely consist of scientific experts. The Federal Ministry of Health also has administrative oversight of a number of federal agencies and research institutes, but research commissioned directly by the Ministry is limited. 
In contrast, the use of scientific evidence is central for the GBA. Scientific evidence plays a key role in many, but not all, decisions of the GBA and practices of using evidence are embedded in the rules of procedures set out in the GBA's by-laws. Two research institutes support the work of the GBA: The Institute for Quality and Efficiency in Health Care (IQWiG), established in 2004, and the Institute for Quality Assurance and Transparency in Health Care (IQTIG), which became operational in 2016. IQWiG, for instance, is mandated to provide health technology assessments and reviews of scientific evidence in relation to the efficacy of pharmaceuticals, diagnostics and medical treatment, evidence-based clinical guidelines and patient information.

However, given its broad remit and the diversity of its regulatory tasks, scientific evidence will be used in different ways for different types of decisions by the GBA. This will depend on the nature of the issue, the types, quality and quantity of studies available, the availability of (international) standards of evidence use (e.g. clinical guidelines, health technology assessment), and the degree to which the issue affects stakeholder interests. As a result, decisions concerning the funding of health technologies, such as pharmaceuticals, diagnostics and medical treatments are typically robustly supported by evidence, while decisions concerning distributional issues such as the geographical coverage of physicians in the ambulatory sector (i.e. capacity planning) show fewer traces of scientific analysis and are more likely to be the product of negotiation between the interest groups represented on the committee. However, in contrast to NICE in England, decisions concerning the package of service do not utilise evidence of cost-effectiveness as a criterion for funding decisions.

Many other organisations of the self-administration, especially at the federal level (e.g. the Sickness Funds, or Federal Association of Physicians), have developed their own research capacity and/or are supported by their own research institutes. These take a variety of organisational and legal forms, and some may be more independent from the organisation commissioning the research than others.

Overall, Germany has deeply rooted systems of democratic accountability, but the decentralised nature of the state limits the stewardship role of the federal government, including the Federal Ministry of Health (BMG), to influence health policy and health service governance. As health system governance is spread across a number of state and non-state actors, there is no single mechanism of decision-making and therefore no single entry point for scientific research. Consequently, there are multiple 
conduits for scientific evidence to enter the policy process, be it in parliament, federal government, the self-administration and its member organisations, and the legal system; with a large number of research institutes, scientific advisory bodies, expert committees and other mechanisms providing scientific advice. However, there are few formal rules that require decision-making to be informed by scientific evidence, with explicit procedures for evidence use in decisions taken by the GBA on inclusions to or exclusions from the statutory benefits package being an exception rather than a norm.

\section{Discussion: Issues And Challenges}

The six countries included in the GRIP-Health programme of work represent a wide range of health policy contexts - ranging from low to high income, covering four continents, and having widely divergent historical and political experiences and socioeconomic profiles. However, in all cases there are core health systems decisions that need to be made, and structures in support of providing evidence to inform such decisions. In all cases (with the possible exception of Germany), Ministries of health were found to be central to these forms of decisions; although we also identified situations where decision authority lies outside the Ministry.

From an institutional perspective, we have particularly focussed on the evidence advisory systems that inform key health policy decisions in each country setting. Each country is of course unique in the historical development of its health systems and associated bureaucracy. As such, we would not expect evidence advisory systems to necessarily look the same across these contexts. Rather, they will have been established, by default or design, within pre-existing administrative structures - products of their specific history which shapes the potential directions and features of any systems being developed. The ultimate goals of improving health and health decision making, however, can be where we look for similarities and comparisons. In particular, it can be assumed that, for evidence advisory systems to function effectively, they must be able to provide robust and high quality syntheses of different forms of evidence, relevant to the specific policy issue at hand, to the appropriate decision makers or bodies responsible for policy decisions which can use them in a timely manner to inform relevant health decisions. We can thus reflect, in a comparative perspective across case study countries, on the alignment of these systems with the decision making needs of the health sector - and of Ministries of 
Health in particular - given these ministries mandate as stewards of population health, and a recognised need for these bodies to use information to inform decisions.

\section{Decisions on Packages of Services}

One theme we can see arising in multiple countries is the central concern across case study countries with the package of health care services to provide to the public - either through state provided health facilities, or within packages of services included in state-regulated insurance programmes. Comparing our case studies illustrates some particular issues with the institutional arrangements in place to supply evidence to inform these decisions. It was in our middle income cases (Colombia and Ghana) where the challenges in the systems to inform such decisions were most visible. Indeed, in the lower income settings studied (Ethiopia and Cambodia), local stakeholders did not raise these decisions as primary concerns in interviews potentially due to the inability to provide comprehensive packages of care in the first place. When needs are well beyond resources available, and funds for services are highly dependent on both donors and individuals' out of pocket expenditures, there may be little perceived need to have an evidence base on which to judge inclusion or exclusion of a formal package of services. Alternatively, in our high income settings (England and Germany), there were already well established formal systems informing these decisions, albeit very different in structure. There are also notable differences in the type of evidence included in such decisions between both countries, with NICE in England basing its recommendations on cost effectiveness, a criterion which is absent from the German regulatory approach.

In our middle income settings, decisions about the package of health services were indeed being made, but without a fully established structure to provide evidence to inform such decisions. In Ghana, the National Health Insurance Agency (NHIA) has had to decide what to include in its service package, yet a national framework for health technology assessment (HTA) has not yet been implemented. This is despite the fact that the country supported the HTA resolution at the 67th World Health Assembly (2014) requiring all countries to work towards Universal Health Coverage using HTA as a tool for priority setting. At the time of our fieldwork, the country was only piloting HTA as a tool to guide prioritisation decisions within the NHIA. So steps are being made, but the evidence advisory systems needed for particular decisions may not yet be fully formed. 
In Colombia there has indeed been a recent attempt to establish a formal Health Technology Assessment body. The local body (IETS) was largely modelled on NICE in England, with key personnel from NICE involved in the establishment and governance of the body, but its institutional placement and level of influence differs considerably from the English body. IETS was not set up with a formal government mandate to make decisions for service provision in Colombia, and thus is merely advisory. The insurance based system in Colombia is also very different to the English National Health Service, and there appears to be no strong agreement on the appropriateness of using HTA metrics (like cost-effectiveness) to make decisions about services in this setting. As Chap. 9 further notes, many decisions on health service provision end up being resolved by the court system rather than the government.

\section{Use of Routine Data to Guide Decisions}

A second theme that arose in our lower and middle income settings were issues around how systems work to provide routine data to guide health sector decision making. Interestingly, the robustness of the system to use such data was not simply a reflection of the income level of the country. Indeed, it was Ethiopia that appeared to have a particularly strong emphasis on such data, building systems to use it for health sector planning. In contrast, capacity issues over data use were raised in Cambodia, along with an identified challenge in gathering data from private health providers who represent the majority of service provision in the country.

Ghana presented another case to look at how well systems of routine data align with decision structures in the country. As detailed in more depth in Chap. 4, Ghana has had investment and capacity building in its routine data system. However, that chapter further explored how such data can end up being used in an institutionalised decision making process that has strong donor influence, with international bodies playing a large role in the annual processes in which routine data are used to construct national indicators that inform the health sector plan. The analysis explored how this can result in a parallel system of evidence use and planning that was outside the normal health sector administrative hierarchy. Ethiopia, on the other hand, appeared to more strongly centrally control its planning activities, including resisting donor influence as reported in our case study. 
In Germany and England, there is substantial infrastructure to collect routine data across both health systems, supported by a number of bodies created for this purpose. For a long time, data collection in England has benefited from an integrated approach applied to the NHS as a whole, with Hospital Episode Statistics being a prime example for a comprehensive and systematic approach to data collection across all hospitals in England since 1987. In Germany, such systematic data collection tends to be a more recent development, as national approaches to data collection have typically been afflicted by concerns around the privacy of personal data. In recent years, however, efforts have been made to improve the collection of routine data, for example, through the creation of the IQTiG, which is mandated with the collection of data on the quality of care across the health system.

\section{Health-Issue Specific Decisions}

In addition to deciding which health services to provide within national service packages, and the use of data to inform sector-wide planning, a third key area for evidence use in health policymaking is captured within the process of decision making within health-specific programmes. Indeed, a great deal of literature on the topic of evidence-informed policymaking in the health sector refers to how pieces of evidence can inform health issue specific decisions - such as choices between possible interventions. For example, we can see literature concerned with improving evidence use for malaria (Woelk et al. 2009), for HIV (Auerbach 2008), or for mental health decisions (Weisz et al. 2005), amongst others.

Our findings show that the institutional structures to serve these needs can be varied. Some countries will have ministerial departments that undertake research that links to other departments with specific health remits. Yet in most cases, evidence to inform decisions on health topics comes from outside Ministries of Health. This can come in the form of explicitly commissioned research dictated by, or initiated by ministry actors; or alternatively provided by external actors - be they research bodies, think tanks, international development partners, etc. - who are approaching ministry officials and departments or providing evidence of one form or another.

The use of commissioning research as a strategy relies on having resources available to do so, but also on actors to value evidence sufficient to commit them for this purpose. In many ways, research commissioning by Ministry officials may be interpreted positively as it can ensure the policy relevance 
of evidence generated. Yet heavy reliance on internal commissioning also risks narrowing the focus of evidence provision to those issues pre-identified or preferred by officials, potentially to the detriment of other options that have not been considered for any number of political reasons. Yet reliance on outside groups presenting information is not without challenges as well. While a much larger number of groups may provide evidence from outside official bodies, there is a risk this process is dominated by particular well-networked or well-resourced organisations, which can also direct political attention using evidence to support a given case. In our aid-dependent settings, as discussed in Chap. 10, there were concerns raised about how donor influence shapes the evidence that is created and provided to governments at times.

\section{Arm's Length Public Health Advisory Bodies}

Despite the vast differences between country settings, an institutional arrangement seen in multiple countries was the establishment of officially mandated advisory bodies that sit at 'arm's length' to the Ministry of Health. In three cases, this was explicitly a body tasked with providing advice in relation to public health: the Ethiopia Public Health Institute, the Cambodian National Institute of Public Health, and Public Health England were all mentioned as playing such roles to inform policy and practice while being placed outside of the Ministry system.

In these three cases of arm's length public health bodies, we found that they all have clear mandates to provide evidence to the decision process with appropriate linkages to do so, and in some cases their placement appeared to work well to ensure the independence of evidence advice while still remaining relevant to local needs (this was not explicitly investigated, though, in all cases). The main issue identified, however, related to capacity - with the Ethiopian and Cambodian examples showing serious limitations. In Cambodia, financial constraints were highlighted as a particular challenge. So, for example, the ability to raise salary costs by undertaking work for non-state actors was noted as a key challenge preventing the National Institute of Public Health from achieving greater potential to inform and advise the government for policymaking. In Ethiopia, the Public Health Institute also faced resource challenges, but these were presented as related to human capacity. Thus even though a directorate existed to provide policy briefs to government, only a handful were produced at the time of the fieldwork due to the limited number of staff available. 


\section{Conclusions}

This chapter began by discussing the stewardship function of ministries of health, which provides them with a mandate for improving population health, but further can be seen to provide a mandate to shape the evidence advisory systems in place to inform health policy. However, when looking across a range of countries, with differing contextual features, we see a number of ways that such evidence advisory systems may function (or not) to meet the needs of health policy making. We can further identify key issues related to the ability of Ministries to serve in this stewardship role in relation to policy-relevant evidence.

In terms of authority over health policymaking itself, Ministries of Health are responsible for many key health decisions in our case study countries. Yet there are several instances where the institutional arrangements in place shift key decisions outside of direct Ministerial authority. This is perhaps most evident in Germany where the corporatist approach to governance means that actors representing the self-administration possess a good deal of authority to make decisions. As such, ministerial information sources in Germany may work in parallel with evidence systems informing the corporatist system. In Colombia, on the other hand, the Constitutional Court makes fundamental decisions on availability and provision of health services and treatments, with clear implications for evidence use given the highly technical nature of these decisions (see Chaps. 5 and 6). The judicializiation of health policy decisions in this way, takes not only decision making but also evidence advisory roles outside the control or jurisdiction of the ministry of health in that setting (Hawkins and Alvarez Rosete 2017).

Similarly, in settings in which health policy decisions were made within the legislative branch (e.g. at parliamentary level), Ministries of Health would not necessarily be involved in structuring the systems of evidence advice. Public health and health promotion decisions affecting whole populations might at times be decided at parliamentary level - for example in the UK or in Ghana. Yet there appears to be minimal involvement of ministries of health in shaping or informing the evidence advisory systems that serve the legislatures in these cases. Again, they appear to be constructed in parallel to ministry systems, or outside ministerial jurisdiction. Donor influence and control of health decisions in aid-dependent settings could lead to further cases where ministries did not have direct control over systems of evidence provision (explored more in Chap. 10). 
We thus find important limitations to the idea that Ministries of Health can serve as comprehensive stewards of systems of health evidence advice, as their ability to do so will be strongly shaped by their authority and control over particular health decision types. That said, we maintain that Ministries of Health, in all case country settings, have significant roles and responsibilities for health decisions even in cases where certain key health topics are addressed in other forums or at different levels of governance. We conclude that there is a clear need for both financial and human resource capacity to ensure well-functioning evidence advisory systems serve the needs of decision makers. That said, capacity was not the only issue identified, nor were lower resources always an insurmountable challenge. Ethiopia's strength in use and control of routine data sources for planning stands out in comparison to Cambodia, which is ranks as having a marginally higher national income (World Bank 2017), but which has struggled to establish robust data management systems. Ghana has invested in its data system, but the institutional systems in place can dictate how data were subsequently used to inform health sector planning; with findings showing that routine data could end up informing planning systems greatly influenced by external donors (see Chap. 4). Even in higher income settings, we identified issues beyond those of capacity. England and Germany demonstrate a high level of scientific expertise and evidence advisory capacity, but they rely on differing mixes of systems, agencies, and bodies. The generation or synthesis of evidence through commissioned research, or through the convening of advisory groups on an $a d$-hoc basis, may reflect a positive step to ensure evidence is policy relevant, but may also lead to evidence only being provided when it is politically expedient or for issues which are already on the political agendas.

Comparing countries of varying income levels illustrates that the realm of government bodies (some at arm's length, others not) appears much more crowded in England and Germany than in our other case study countries. This may not be surprising, however, as it is possible that as institutional structures evolve over time, there will be increasing numbers of organisations, a greater division of work, and potential for higher levels of specialisation. While outside the scope of analysis here, there could be future work investigating questions around this in more depth - potentially considering levels of capacity and resource; the prominence given to evidence to inform decision; and the time and stability required to establish types of infrastructure arrangements. 
While the World Health Organization has indeed identified Ministries of Health as the stewards of their population's health, decision making that shapes health outcomes may be located in a number of forums, with only some key decisions taken in Ministries of Health. However, Ministries of Health remain central to health policy decisions in all settings. We have argued here that understanding when and why policy-relevant evidence serves the needs of health decisions requires an explicitly institutional lens that can consider the structural arrangements and links between sources and providers of evidence and the relevant decision making points. Evidence can improve health decisions and outcomes, but only if it is provided in a comprehensive and timely manner to inform key decisions. Ultimately it will be the underlying structures and links of the evidence advisory systems in each country that dictate when, how, and how well this takes place.

\section{REFERENCES}

[Cambodia] National Institute of Statistics Directorate for Health. 2015. Cambodia demographic and health survey 2014. Phnom Penh: Cambodia National Institute of Statistics Directorate for Health and ICF International.

[Germany] Federal Ministry of Health. 2015. Bundestministerum für Gesundheit. http://www.bmg.bund.de/. Accessed 5/2/2015.

African Health Observatory. 2014. Ethiopia health system: Health information, research, evidence and knowledge. http://www.aho.afro.who.int/profiles_ information/index.php/Ethiopia:Health_information,_research,_evidence_ and_knowledge. Accessed Sept 2016.

Alvarez-Rosete, Auturo. 2007. Modernising policy making. In Health policy and politics, ed. A. Hann, 41-57. Aldershot: Ashgate.

Alvarez-Rosete, Arturo. 2008. The role of the state in public health. In International encyclopedia of public health, ed. Kris Heggenhougen, 211-218. Oxford: Academic Press.

Auerbach, Judy. 2008. Confronting the 'evidence' in evidence-based HIV prevention: Summary report. San Francisco: San Francisco AIDS Foundation.

Bell, Stephen, and Andrew Hindmoor. 2009. Rethinking governance: The centrality of the state in modern society. Cambridge: Cambridge University Press.

Bernal, Oscar, Juan Camilo Forero, and Ian Forde. 2012. Colombia's response to crisis. BMJ 344: 25.

Bevir, Mark. 2010. Democratic governance. Princeton: Princeton University Press.

Boyle, Seán. 2011. United Kingdom (England) health system review. London: European Observatory on Health Systems and Policies. 
Cambodia Ministry of Health. 2008. Health strategic plan 2008-2015. Accontability, efficiency, quality, equity. Phnom Penh: Cambodia Ministry of Health.

Castro, Hector. 2014. Assessing the feasibility of conducting and using health technology assessment in Colombia. The case of severe haemophilia. Doctor of Public Health, London School of Hygiene and Tropical Medicine.

Chalmers, Iain. 2003. Trying to do more good than harm in policy and practice: The role of rigorous, transparent, up-to-date evaluations. The Annals of the American Academy of Political and Social Science 589 (1): 22-40.

Chalmers, Iain, Larry V. Hedges, and Harris Cooper. 2002. A brief history of research synthesis. Evaluation \& the Health Professions 25 (1): 12-37. https:// doi.org/10.1177/0163278702025001003.

Craft, Jonathan, and Michael Howlett. 2012. Policy formulation, governance shifts and policy influence: Location and content in policy advisory systems. Journal of Public Policy 32 (2): 79-98.

Davies, Glyn, and Michael Keating, eds. 2000. The future of governance. St Leonards: Allen \& Unwin.

Dodgson, Richard, Kelley Lee, Nick Drager, and World Health Organization. 2002. Global health governance: A conceptual review. London School of Hygiene and Tropical Medicine and World Health Organization.

Downie, Richard. 2016. Sustaining improvements to public health in Ethiopia. Washington, DC: Center for Strategic and International Studies.

Durán, Antonio, Joseph Kutzin, José M. Martin-Moreno, and Phyllida Travis. 2011. Understanding health systems: Scope, functions and objectives. In Health systems: Health, wealth, society and wellbeing. Maidenhead, Open University Press and McGraw-Hill, ed. Joseph Figueras and Martin McKee, 19-36. Maidenhead: Open University Press.

Ethiopia Federal Ministry of Health. 2014. Ethiopia's fifth national health accounts, 2010/2011. Addis Ababa: Federal Ministry of Health.

Ethiopian Academy of Science. 2013. Report on mapping the health Reserach landscape in Ethiopia. Addis Ababa: Ethiopian Academy of Science.

Gaym, Asheber. 2008. Health research in Ethiopia-Past, present and suggestions on the way forward. Ethiopian Medical Journal 46 (3): 287-308.

Hafner, Tamara, and Jeremy Shiffman. 2012. The emergence of global attention to health systems strengthening. Health Policy and Planning 28 (1): 41-50.

Halligan, John. 1995. Policy advice and the public service. In Governance in a changing environment, ed. Guy Peters and Donald J. Savoie, 138-172. Montreal: Canadian Centre for Management Development.

Hanney, Stephen, Shyama Kuruvilla, Bryony Soper, and Nicholas Mays. 2010. Who needs what from a national health research system: Lessons from reforms to the English Department of Health's R\&D system. Health Research Policy and Systems 8 (1): 11. 
Hawkins, Benjamin, and Arturo Alvarez Rosete. 2017. Judicialization and health policy in Colombia: The implications for evidence-informed policymaking. Policy Studies Journal. https://doi.org/10.1111/psj.12230.

Hogwood, Brian W., and Lewis A. Gunn. 1984. Policy analysis for the real world. Oxford: Oxford University Press.

Hustedt, Thurid, and Sylvia Veit. 2017. Policy advisory systems: Change dynamics and sources of variation. Policy Sciences 50 (1): 41-46.

Jones, Harry, and Camboida Economic Associate Centre for Policy Studies. 2013. Building political ownership and technical eadership: Decision-making, political economy and knowledge use in the health sector in Cambodia. London: Overseas Development Institute.

Kickbusch, Ilona, and David Gleicher. 2012. Governance for health in the 21st century: World Health Organization, Regional Office for Europe.

Kickbusch, Ilona. 2002. Perspectives on health governance in the 21 st century. In Marhall Marinker and Martin Mckee (eds) Health targets in Europe: Policy, progress and promise, 218. London: BMJ Books.

Kjaer, Anne Mette. 2004. Governance: Key concepts. Cambridge: Polity Press.

. 2011. Rhodes' contribution to governance theory: Praise, criticism and the future governance debate. Public Administration 89 (1): 101-113.

Kooiman, Jan. 2000. Societal governance: Levels, modes and orders of socialpolitical interaction. In Debating governance: Authority, steering and democracy, ed. Jon Pierre, 138-167. Oxford: Oxford University Press.

Koon, Adam D., Krishna D. Rao, Nhan T. Tran, and Abdul Ghaffar. 2013. Embedding health policy and systems research into decision-making processes in low-and middle-income countries. BMC Health Research Policy and Systems $11(1): 30$.

LaRocca, Rebecca, Jennifer Yost, Maureen Dobbins, Donna Ciliska, and Michelle Butt. 2012. The effectiveness of knowledge translation strategies used in public health: A systematic review. BMC Public Health 12 (1): 751.

Lavis, John N., G. Emmanuel Guindon, David Cameron, Boungnong Boupha, Masoumeh Dejman, Eric J. Osei, and Ritu Sadana. 2010. Bridging the gaps between research, policy and practice in low- and middle-income countries: A survey of researchers. CMAJ. https://doi.org/10.1503/cmaj.081164.

Lewis, Richard, Arturo Alvarez-Rosete, and Nicholas Mays. 2006. How to regulate bealth care in England? An international perspective: King's Fund.

McQueen, David, Matthias Wismar, Vivian Lin, Catherine M. Jones, and Maggie Davies, eds. 2012. Intersectoral governance for bealth in all policies. Structures, actions and experiences. Malta: World Health Organization on behalf of the European Observatory on Health Systems and Policies.

NICE. 2017. NICE Charter. National Institute for Health and Care Excellence. https://www.nice.org.uk/media/default/about/who-we-are/nice_charter.pdf 
Nutley, Sandra M., Isabel Walter, and Huw T.O. Davies. 2007. Using evidence: How research can inform public services. Bristol: The Policy Press.

Parkhurst, Justin. 2017. The politics of evidence: From evidence based policy to the good governance of evidence. Abingdon: Routledge.

Piere, Jan, and B. Guy Peters. 2000. Governance, politics and the state. Basingstoke: Macmillian.

Pierre, Jon. 2000. Debating governance: Authority, steering and democracy. Oxford: Oxford University Press.

Reich, Michael R. 2002. Reshaping the state from above, from within, from below: Implications for public health. Social Science \& Medicine 54 (11): 1669-1675.

Rhodes, Roderick Arthur William. 1996. The new governance: Governing without government. Political studies 44 (4): 652-667.

Rhodes, Rod A.W. 1997. Understanding governance: Policy networks, governance, reflexivity and accountability. Philadelphia: Open University Press.

Richards, David, and Martin J. Smith. 2002. Governance and public policy in the UK. Oxford: Oxford University Press.

Rosenau, James N. 1995. Governance in the twenty-first century. Global Governance 1 (1): 13-43.

Saltman, Richard B., and Odile Ferroussier-Davis. 2000. The concept of stewardship in health policy. Bulletin of the World Health Organization 78 (6): 732-739.

Saltman, Richard B., Antonio Durán, and Hans F.W. Dubois. 2011. Governing public hospitals. Reform strategies and the movement towards institutional autonomy. Copenhagen: European Observatory on Health Systems and Policy, WHO Regional Office for Europe.

Shaw, Sara E., Jill Russell, Trisha Greenhalgh, and Maja Korica. 2014. Thinking about think tanks in health care: A call for a new research agenda. Sociology of Health o Illness 36 (3): 447-461.

Shergold, Miriam, and Jonathan Grant. 2008. Freedom and need: The evolution of public strategy for biomedical and health research in England. Health Research Policy and Systems 6 (1): 2.

Stoker, Gerry. 1998. Governance as theory: Five propositions. International Social Science Journal 50 (155): 17-28.

UK Government. 2013. What works: Evidence centres for social policy. London: UK Cabinet Office.

van Kammen, Jessika, Don de Savigny, and Nelson Sewankambo. 2006. Using knowledge brokering to promote evidence-based policy-making: The need for support structures. Bulletin of the World Health Organization 84: 608-612.

Weisz, John R., Irwin N. Sandler, Joseph A. Durlak, and Barry S. Anton. 2005. Promoting and protecting youth mental health through evidence-based prevention and treatment. American Psychologist 60 (6): 628. 
WHO. 2000. The world health report 2000 - Health systems: Improving performance. Geneva: World Health Organization.

. 2003. The world health report 2003. Shaping the future. Geneva: World Health Organization.

- 2007. Everybody's business. Strengthening health systems to improve health outcomes. WHO's framework for action. Geneva: World Health Organization.

- 2008. Primary care. Now more than ever. Geneva: World Health Organization.

WHOROE. 2008. Tallinn charter on health systems, health and wealth. Copenhagen: WHO Regional Office for Europe.

Woelk, Godfrey, Karen Daniels, Julie Cliff, Simon Lewin, Esperança Sevene, Benedita Fernandes, Alda Mariano, Sheillah Matinhure, Andrew D. Oxman, and John N. Lavis. 2009. Translating research into policy: Lessons learned from eclampsia treatment and malaria control in three southern African countries. Health Research Policy and Systems 7 (31): 1-14.

World Bank. 2011. Cambodia - More efficient government spending for strong and inclusive growth: Integrated fiduciary assessment and public expenditure review (IFPER). Phnom Penh: The World Bank.

- 2017. World development indicators database. http://databank.worldbank. org/data/download/GNIPC.pdf

Yamin, Alicia Ely, and Oscar Parra-Vera. 2010. Judicial protection of the right to health in Colombia: From social demands to individual claims to public debates. Hastings International os Comparative Law Review 33: 431.

Open Access This chapter is licensed under the terms of the Creative Commons Attribution 4.0 International License (http://creativecommons.org/licenses/ by $/ 4.0 /$ ), which permits use, sharing, adaptation, distribution and reproduction in any medium or format, as long as you give appropriate credit to the original author(s) and the source, provide a link to the Creative Commons license and indicate if changes were made.

The images or other third party material in this chapter are included in the chapter's Creative Commons license, unless indicated otherwise in a credit line to the material. If material is not included in the chapter's Creative Commons license and your intended use is not permitted by statutory regulation or exceeds the permitted use, you will need to obtain permission directly from the copyright holder.

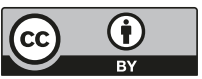

